\title{
Collateral Circulation in Coarctation of Aorta in Infancy and Childhood
}

\author{
RAJAMMA MATHEW $\star$, GEORGE SIMON, and MICHAEL JOSEPH \\ From the Departments of Paediatrics and Radiology, Brompton Hospital, London
}

Mathew, R., Simon, G., and Joseph, M. (1972). Archives of Disease in Childhood, 47, 950. Collateral circulation in coarctation of aorta in infancy and childhood. Forty patients with coarctation of the aorta under the age of 2 years were studied, and a well-developed collateral circulation was present when the coarctation was severe and the sole lesion. In those with an associated congenital heart lesion a collateral circulation was seen in rather more than half. It is suggested that in many patients, the collateral circulation develops during fetal or early postnatal life.

A large collateral circulation is a well-recognized feature of coarctation of the aorta in late childhood and in adults, but there are few references to the earliest age at which it develops or is demonstrable in angiograms.

Bahn, Edwards, and DuShane (1951) described necropsy studies in 3 infants who had coarctation of the aorta. They concluded that patients with coarctation of the aorta distal to the ductus arteriosus have collaterals bypassing the aorta and that these develop during fetal life.

\section{Material and Method}

During the years 1966-1971, 42 patients under the age of 2 years with coarctation of the aorta were admitted to the Brompton Hospital with cardiac failure and/or significant upper limb hypertension, and all were studied with cardiac catheterization and biplane Elema angiography. The arterial pressure was recorded in the axillary artery or in the aorta proximal to the coarctation site. Two of these patients were excluded from our analysis because the angiograms were of inadequate quality to show or exclude collateral circulation.

From the analysis of the angiograms the following data were recorded.

Site of coarctation. The site of the coarctation was more or less at ductal level in all but 2 patients in whom there was interruption at the level of the arch.

Severity of coarctation. There was some difficulty in assessing the severity of the coarctation, since the

\footnotetext{
Received 3 May 1971.

^Present address: The Children's Hospital Medical Centre, Department of Cardiology, 300 Longwood Avenue, Boston, Massachusetts 02115 , U.S.A.
}

gradient as measured by a single catheter is not satisfactory; more reliance was, therefore, placed on the degree of reduction of the femoral pulses on palpation, and the degree of filling or absence of filling (except from collaterals) of the aorta distal to the narrowing. If filling was slight, the narrowing was considered to be severe. However good distal filling can occur with gross narrowing (Fig. 1 and 2).

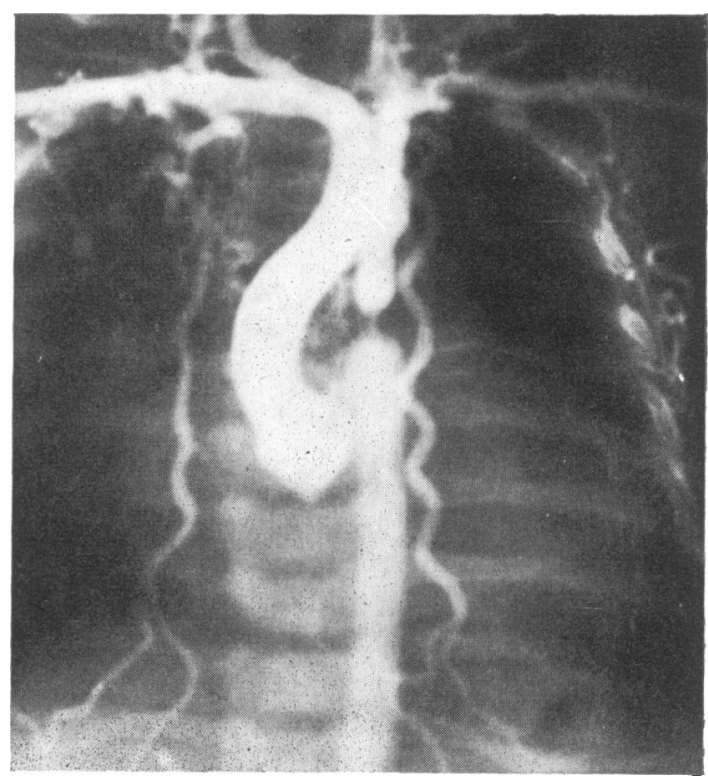

Fig. 1.-Coarctation of the aorta. Female aged 6 weeks showing dilated internal mammary and upper mediastinal arteries. 


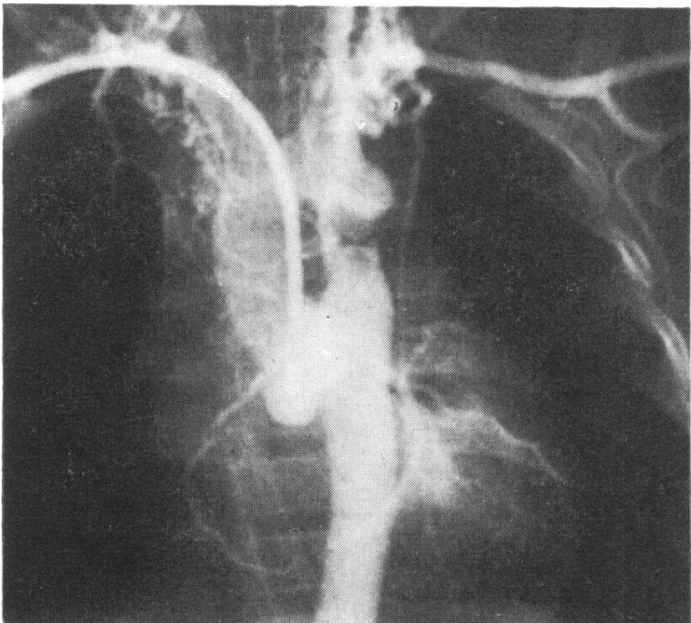

FIG. 2.-Coarctation of the aorta. Female aged 9 months showing large collaterals in the lower neck and subscapular regions. BP $75 / 45 \mathrm{mmHg}$.

Presence or absence of collateral circulation. Filling of the internal mammary arteries is commonly seen in angiograms of infants without an aortic anomaly, and by reference to the appearances of these children, it was possible to be sure a well-developed collateral circulation was present if the arteries were larger than the control group, particularly the appearance of these vessels and their branches below the level of the fifth

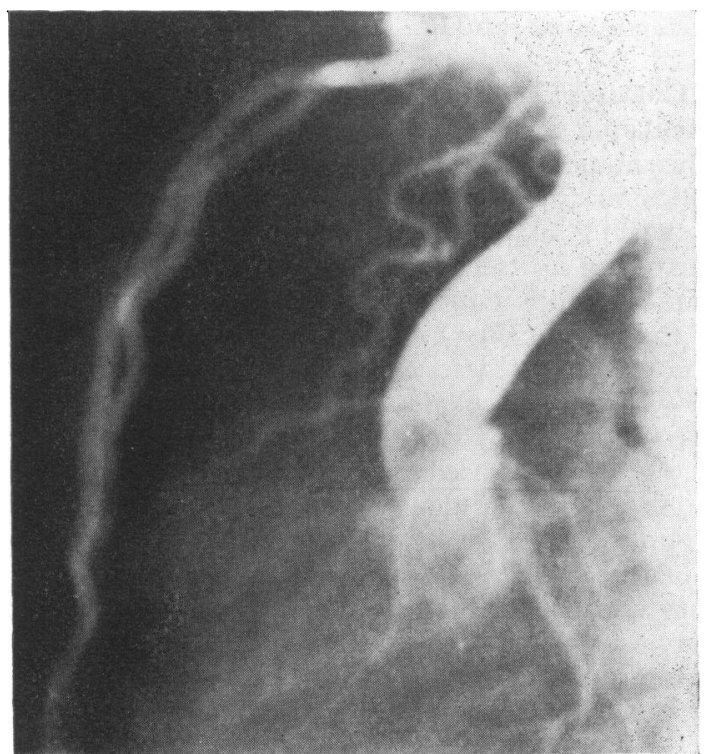

FIG. 3.-Coarctation of the aorta. Same patient as Fig. 1 (lateral view) showing the dilated internal mammary and upper mediastinal arteries. rib anteriorly. If a well-developed collateral circulation is present, these distal branches are dilated, and may form anastomoses with intercostal arteries and thus the aorta (Fig. 1 and 3).

A well-developed vascular bed in the lower neck or shoulder area (Fig. 2 and 4 ) is also evidence of a collateral circulation, even if the vessels cannot be traced down from these regions to the distal aorta.

The 40 patients were divided into 4 groups.

Group 1: the coarctation was the only abnormality.

Group 2: the coarctation was associated with some other lesion, not in groups 3 or 4 .

Group 3: the coarctation was associated with a significant left-to-right shunt.

Group 4: the coarctation was associated with complicated intracardiac defects.

If the infants had tachypnoea, an enlarged liver, and feeding difficulties apparently due to the heart lesion, or gave a previous history of these features, they were regarded as having cardiac failure or of having been in cardiac failure previously.

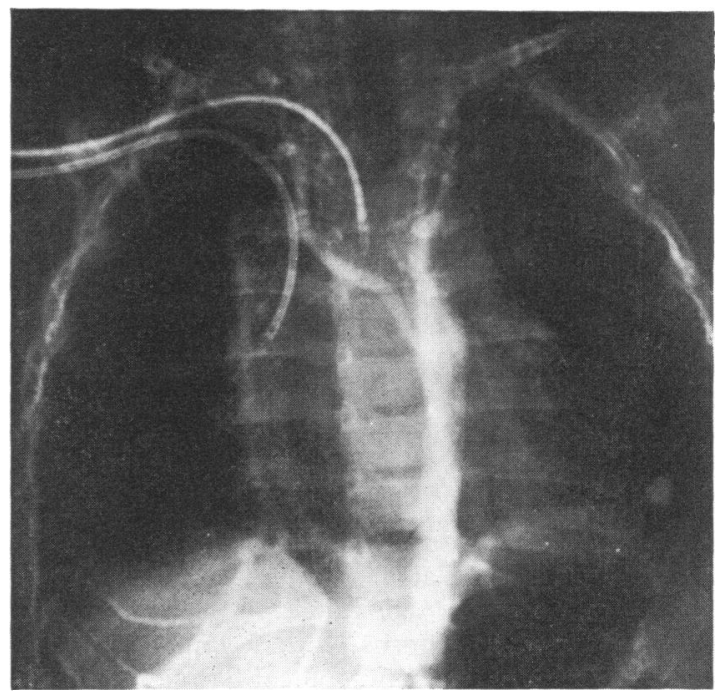

FIG. 4.-Coarctation of the aorta. Male aged 6 weeks showing dilated internal mammary artery on the right side only, and a large branch from the innominate artery

to supply the descending aorta below the coarctation.

\section{Results}

Group 1 (9 patients). One patient also had partial anomalous pulmonary venous drainage, but since the calculated shunt was small, he is included in this group. There were 7 males and 2 females. Their age range on admission was from 8 days to 15 months, with 6 less than 6 months old. 4 patients at the time of admission were in congestive cardiac failure. Their ages were 8 days, 3 weeks, 2 months, and 3 months. One 6-month-old infant 
had a history of having had cardiac failure in the newborn period. The last 4 were asymptomatic, but had upper limb hypertension. Femoral pulses were weak or absent in all these patients. In the plain $x$-ray, the heart size and pulmonary vessels were judged to be normal in 7, while 2 were considered to have cardiomegaly, though the difficulties of assessing this at such a young age are recognized.

The arterial pressure proximal to the coarctation at catheterization ranged from $75 \mathrm{mmHg}$ to 140 $\mathrm{mmHg}$, with an average of $110 \mathrm{mmHg}$. In one, the pressure was not recorded but there was systemic hypertension by auscultation.

Group 2 (7 patients). There were 6 females and 1 male. Their age range on admission was from 13 days to 1 year, with 6 less than 6 months old. All patients were admitted in congestive cardiac failure except one, the 1-year-old infant. Femoral pulses were weak or absent in all.

In the plain $x$-ray, the appearances were normal in 2. The rest showed cardiac enlargement, and 3 also showed dilated lung vessels. This rather heterogeneous group included 4 patients with evidence of a poorly contracting left ventricle on angiography, 2 of whom were proved to have endocardial fibroelastosis at necropsy. One patient had mitral incompetence, and 2 had raised pulmonary vascular resistances of 6.6 units, and 43 units per square metre. This last patient had resection of the coarctation, but died at home some weeks later. The arterial pressure recorded at catheterization ranged from $62 \mathrm{mmHg}$ to $146 \mathrm{mmHg}$ with an average of $106 \mathrm{mmHg}$.

Group 3 (13 patients). The sites of the shunts are shown in the Table. There were 7 females and 6 males. Their age range on admission was from 5 days to 13 months, with 9 younger than 2 months. All had evidence of cardiac failure, and the physical signs were those of the shunt and the coarctation. The plain $x$-ray showed cardiomegaly, and dilated hilar vessels in 6 patients, and in one there was cardiomegaly, but the lung vessels were within normal limits. In 3 the $x$-ray was normal, and in 3 it was unsuitable for analysis.

The electrocardiographic pattern was influenced by the level of the shunt. The arterial pressure recorded at catheterization ranged from $78 \mathrm{mmHg}$ to $166 \mathrm{mmHg}$, with an average of $105 \mathrm{mmHg}$.

Group 4 (11 patients). 7 had transposition of the great vessels in addition to the coarctation, and 4 had either single ventricle or a double outlet right ventricle. There were 6 females and 5 males.
TABLE

Group 3: Coarctation and Left-to-right Shunts

\begin{tabular}{c|c|l|l}
\hline Case No. & Age & Sex & \multicolumn{1}{|c}{ Diagnosis } \\
\cline { 1 - 2 } 1 & $7 \mathrm{dy}$ & F & PDA; ASD; VSD \\
2 & $7 \mathrm{wk}$ & M & PDA \\
3 & $16 \mathrm{dy}$ & F & VSD \\
4 & $13 \mathrm{mth}$ & F & PDA (small) \\
5 & $9 \mathrm{wk}$ & M & PFO; PDA \\
6 & $5 \mathrm{wk}$ & M & ASD \\
7 & $2 \mathrm{wk}$ & M & PDA; VSD \\
8 & $3 \mathrm{mth}$ & F & PDA; VSD \\
9 & $10 \mathrm{wk}$ & F & VSD \\
10 & $3 \mathrm{wk}$ & M & VSD; PDA \\
11 & $5 \mathrm{dy}$ & F & ASD; VSD; PDA \\
12 & $1 \mathrm{mth}$ & F & VSD; hypoplastic arch \\
13 & $6 \mathrm{dy}$ & $\mathrm{M}$ & ASD; VSD \\
\hline
\end{tabular}

PDA, persistent ductus arteriosus; ASD, atrial septal defect; VSD, ventricular septal defect; PFO, patent foramen ovale.

Their age range on admission was from 2 days to 2 months. All had evidence of cardiac failure. The physical signs were determined by the heart lesion with the addition of those due to the coarctation.

The plain $x$-ray was unsatisfactory for analysis in 2 patients. It was normal in 2 , both with transposition of the great vessels. The remaining 7 showed cardiomegaly, and dilated hilar and midlung vessels. The ECG was influenced by the cardiac lesion. The arterial pressure at catheterization ranged from $58 \mathrm{mmHg}$ to $130 \mathrm{mmHg}$, with an average of $80 \mathrm{mmHg}$.

Collateral circulation. A good collateral circulation was seen in more than half the patients. The number of the patients with and without collateral circulation in the different age groups is shown in Fig. 5. In group 1, the degree of narrowing in itself was enough to cause hypertension, and thus either heart failure or recognition of the abnormality by the clinician. The obstruction was thus severe, and all patients in this group showed a good collateral circulation.

In other groups, the associated cardiac abnormality was often the predominant lesion, and the coarctation was an additional finding. Nevertheless, in group 2, a good collateral circulation was seen in 3 of the 7 patients, 2 of these having high pulmonary vascular resistances, and the third endocardial fibroelastosis.

In group 3, a good collateral circulation was seen in 7 of the 13 patients, and in group 4, in 6 of the 11 patients. However, in group 4, the collateral vessels were relatively small in 4 of the patients, and in 2 there was only some dilatation of the internal mammary arteries. 


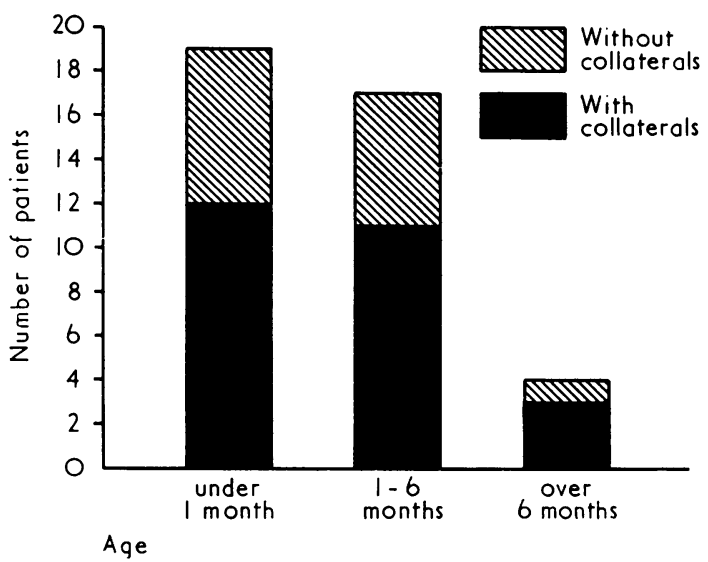

FIG. 5.-Number of patients with and without a visible collateral circulation in the different age groups.

\section{Discussion}

This study indicates that in coarctation of the aorta of some severity, a good collateral circulation can be seen in angiograms in many patients, either soon after birth, or at less than 2 months of age. When the coarctation is the sole lesion, and causes systemic hypertension and/or heart failure, it is likely to be severe, and in our patients a collateral circulation was well developed by the time the infant was investigated. This suggests that the collateral circulation is likely to have developed either during fetal life or during the early weeks of postnatal life.

When the coarctation is accompanied by additional heart lesions, clinical assessment of the severity of the aortic narrowing is less certain; nevertheless, a well-developed collateral circulation was present in 17 out of 31 such patients. The sole exception to this has been in the 4 with an associated endocardial fibroelastosis, in 2 of whom systemic hypertension was also present.

The relation of systemic hypertension and the presence of a collateral circulation was interesting. In all but one patient in group 1, hypertension (more than $100 \mathrm{mmHg}$ systolic) was present and in all a good collateral circulation was present. The mean pressure for the group was $111 \mathrm{mmHg}$. In each of the individual groups, a greater number had hypertension associated with a collateral circulation, but the difference in the mean recording of blood pressures was not significant between those with a collateral circulation and those without. However, when all the four groups were taken together, the meun pressure in those with a collateral circulation was $112 \mathrm{mmHg}$, and in those 13 without a collateral circulation it was $85 \mathrm{mmHg}$; this difference is just significant at the $5 \%$ level. Furthermore, the total number of patients with collateral circulation (all groups), who showed a pressure of 100 $\mathrm{mmHg}$ or more, was 19 out of a possible 25 . This compares with only one patient out of a possible 13 in those without a collateral circulation who showed a pressure of more than $100 \mathrm{mmHg}$. Clearly, therefore, there is a relation between systemic hypertension, and the development of a good collateral circulation, but occasionally hypertension is present without a collateral circulation and more commonly a collateral circulation is present without hypertension.

The ECG did not show any consistent pattern which could be related to the presence or absence of a good collateral circulation.

We are grateful to Dr. G. Miller for the data from the catheter studies, and the Illustration Department of the Royal Marsden Hospital for the photographic reproductions.

\section{REFBRENCB}

Bahn, R. C., Edwards, J. E., and DuShane, J. W. (1951). Coarctation of the aorta as a cause of death in early infancy. Pediatrics, 8, 192.

Correspondence to Dr. G. Simon, Department of Radiology, Brompton Hospital, Fulham Road, London SW3 6HP. 